\title{
Nanotechnology, uncertainty and regulation. A guest editorial
}

\author{
Simone Arnaldi • Alessia Muratorio
}

Received: 3 November 2013 / Accepted: 5 November 2013

(C) Springer Science+Business Media Dordrecht 2013

\begin{abstract}
Nanotechnology has been established as a priority research and policy focus, cutting across several R\&D fields from pharmaceutics, food and electronics. The raise of nanotechnologies has been accompanied by an enduring uncertainty characterising the developments of the scientific knowledge related to this field, as well as the social trajectories of technological applications. Such a condition inevitably affects regulatory responses to such technologies, their development and their uses. This special issue addresses this junction between uncertainty and regulation. With no ambition of providing a comprehensive assessment of such a complex issue, this collection of articles examines three relevant dimensions for understanding uncertainty in nanotechnology regulation, which can be useful entry points for further reflection and discussion: scientific uncertainty, regulatory fragmentation, social actors' opinions about and attitudes to nanotechnology and regulation.
\end{abstract}

Nanotechnology has been established as a priority research and policy focus, cutting across several R\&D fields from pharmaceutics, food and electronics. Such a growing attention has been fuelled by expectations about the positive impacts of nanotech on the environment, human health, and society, which often resulted in outright and enthusiastic support (e.g. [2,11]). At the same

S. Arnaldi · A. Muratorio $(\bowtie)$

Centre for environmental, ethical, legal and social decisions on emerging technologies, University of Padua, Viale Porta Adige 45, 45100 Rovigo, Italy

e-mail: alessia.muratorio@unipd.it

S. Arnaldi

Istituto Jacques Maritain, Trieste, Italy time, concerns increased about the possible environmental, health and social effects of nanotechnology, thus leading to a wide range of reactions, from the request for a moratorium (e.g. [1]) to more moderate recommendations asking for more risk research (e.g. [3,4]).

The coexistence of these two contrasting attitudes has been and still is possible because of the uncertainty that characterises nanotechnologies, the developments of the knowledge related to this scientific and technological field, as well as the social trajectories of their applications. While nanotechnology shares this characteristic with other new and emerging technologies, the literature has shown that uncertainty has ambivalent effects. Such a condition inevitably affects regulatory responses to such emerging technologies, their development and their uses. This special issue addresses this junction between uncertainty and regulation in the case of nanotechnology. With no ambition of providing a comprehensive assessment of such a complex issue, this collection of articles examines three relevant dimensions for understanding uncertainty in nanotechnology development, which can be useful entry points for further reflection and discussion.

The first dimension concerns scientific uncertainty. Although the literature on uncertainty and scientific knowledge is vast, opinions converge in describing the intractable nature of uncertainty in new and emerging techno-scientific domains. This refractoriness is, in general terms, rooted in the progressive blurring of the boundaries between the experimental settings of research and the operational settings of manufactured structures and systems, and their natural and human environments (eg. [7,8,13,14]). These blurred boundaries affect the possibilities and conditions of regulation. The lack of scientific knowledge about nanomaterials and systems results in the lack of development in legal 
discourse to describe products and to clearly set legal standards on their safety and efficacy (see Marrani on nanofood regulation in the European Union, in this issue).

The second dimension is internal to regulation and is related to the fragmentation of the regulatory framework. Such a fragmentation is a source of uncertainty in itself, not because it is necessarily related to scientific uncertainty per se, but because it defines diverse, if not divergent, strategies for coping and, most importantly, definitions of the issues to be regulated. In a more traditional fashion from the legal point of view, complex and heterogeneous regulatory frameworks require coordination (e.g. $[5,6,10,12])$, and rules and mechanisms enabling coherence and coordination between different geographical levels, e.g. between EU and Member States (cf. Ponce del Castillo, this issue), as well as between different types of regulation, e.g. soft and hard law mechanisms and tools (cf. Ruggiu, this issue).

The third dimension concerns the social actors' opinions about and attitudes to nanotechnology regulation and, more broadly, to a nanotechnology governance framework. Again, the literature is vast, as it corresponds to the gradual emergence and recent codification of an open view of the policy process that emphasizes inclusiveness of the plurality of beliefs, perceptions, and assumptions that characterize a multi-stakeholder world (e.g. $[9,15,16])$. Given the impact of stakeholders on regulation and policy agendas, how the different actors perceive regulatory issues is therefore important to understand the current evolution of the regulatory frameworks for nanotechnology and, more in general, the division of social labour that is envisaged or advocated in the process of developing nanotechnological applications (cf. Sahoo, Weil, in this special issue, respectively on nanoscientists and firms).

The structure of this special issue corresponds to these three focal points of interest.

Accordingly, the first article deals with the interaction of scientific uncertainty and regulation. Daniela Marrani illustrates the strategies and choices that characterize the EU approach to the regulation of nanotechnology applications in the food sector. Assessing nanofood regulation in the EU, the Author warns that the application of an "incremental approach", which assumes that the regulation in force is adequate for nanotechnology innovations unless new identified risks require specific rules, may create the risk of fragmentation. More importantly, Marrani considers the inconsistent definition of the terms "nanotechnology" and "nanomaterials" as the main problem for the enforcement of regulations and the provision of a wide range of specific regulatory tools for different nanofoods, like the use of positive lists of authorised substances applying only to food contact materials, additives and supplements.

Although regulatory fragmentation is already introduced by Marrani's article, a second pair of articles comments thoroughly on this topic. Aida Ponce del Castillo reviews the plurality and diversity of the current regulatory approaches to nanomaterials in Europe, discussing the major initiatives by the European Commission, the European Parliament and EU Member States, and providing a first-hand take on the Trade Unions' position on nanotechnology regulation. At the EU, the Author presents an overview of the major sectoral legislation (e.g. cosmetics and food); at the national level, the article describes some major national initiatives, in particular those concerning the establishment of reporting systems for nanomaterials, mixtures, articles and consumer products containing them, as an example of how to improve the current governance in the EU and to prevent the risks to human health and the environment. Then, Ponce del Castillo illustrates the Trade Unions' position on nanotechnology regulation and, finally, she presents some conclusions and policy recommendations, taking into consideration the diversity of regulatory approaches. Daniele Ruggiu argues that regulation of nanotechnology is challenged by the twofold temporal horizon of this techno-scientific field. On the one hand, traditional, hard law tools are best suited to govern present day, marketed nanoproducts; on the other hand, soft regulation is best placed to manage flexibly and adaptively future, possible developments of nanotechnology development. The coherence of these two types of regulation is difficult precisely because of their divergent time of reference. In this context, human rights can prove to be an effective coordinating framework. The article argues that, thanks also to their normative structure, they can be the link connecting both the legislation needed for regulating current market applications and the soft regulatory instruments needed for coping with this rapidly evolving field and for fostering stakeholder participation without sacrificing the coherence of the regulatory response.

The last pair of articles examine the "soft aspects" of regulatory policies, presenting national case studies of stakeholder perceptions and opinions. Vivian Weil proposes an empirical research on the attitudes of firms to nanotechnology regulation and the way firms integrate 
responsibility into the management of nanotechnologies. Tracking indicators of responsible management, the research finds out outcomes from telephone conversations with managers or chief technologists at over twenty nanotechnology companies in the mid-west U.S. The attention here focuses on the complete life cycle of their products and the analysis is on responsibility and companies' internal processes for exercising care, concern, and foresight in responsible management. Subhasis Sahoo documents the poorly explored topic of nanotechnology perceptions in developing countries by examining Indian nanoscientists's opinions about which regulatory approach should be implemented for nanotechnology. The articles offers an insight on scientists' views on some crucial issue in nanotechnology regulation: how to strike a balance between research freedom and safety, the need for a regulatory body for nanotechnology, the relevance of labelling as a tool for making informed choices about nanoproducts. Finally, this article further explores how scientists have different views on what responsibility amounts to and under what conditions one is responsible.

Acknowledgments The Editors gratefully acknowledge the financial support from the Istituto Jacques Maritain (Italy), which made the translation of part of these collected articles into English possible.

\section{References}

1. ETC Group (2004) Down on the farm. The impact of nanoscale technologies on food and agriculture. ETC Group, Ottawa

2. European Commission (2004) Nanotechnology: Innovation for tomorrow's world. European Commission, Brussels

3. European Commission (2004b) Towards a European strategy for nanotechnology. Communication from the Commission, $\operatorname{COM}(2004) 338$ final.
4. European Commission (2008) Commission recommendation on a code of conduct for responsible nanosciences and nanotechnologies research, $\operatorname{COM}(2008) 424$ final.

5. Falkner R, Breggin L, Jaspers N, Pendergrass J, Porter R (2010) International coordination and cooperation: The next agenda in nanomaterials regulation. In: Hodge GA, Bowman $\mathrm{DM}$, Maynard AD (eds) International handbook on regulating nanotechnologies. Edward Elgar, Cheltenham, pp 508-524

6. Falkner R, Jaspers N (2012) Regulating nanotechnologies: Risk, uncertainty and the global governance gap. Global Environmental Politics 12(1):30-55

7. Felt U, Wynne B (2007) Taking European knowledge society seriously. Report of the expert group on science and governance to the science, economy and society directorate. European Commission, Brussels

8. Funtowicz S, Ravetz J (1993) Science for the post-normal age. Futures 25(7):739-755

9. Malsch I (2012) Governing nanotechnology in a multistakeholder world. Nanoethics 7(2):161-172

10. Marchant GE, Sylvester DJ, Abbott KW, Danforth TL (2010) International harmonization of regulation of nanomedicine. Studies in Ethics, Law, and Technology. 3(3), DOI: 10.2202/ 1941-6008.1120.

11. Nstc - National Science and Technology Council (1999). Nanotechnology. Shaping the World Atom by Atom. Retrieved July 31, 2013, from http:/www.whitehouse.gov/ administration/eop/ostp/nstc/docsreports/archives

12. Pariotti E (2011) Normatività giuridica e governance delle tecnologie emergenti. In: Guerra G, Muratorio A, Pariotti E, Piccinni M, Ruggiu D (eds) Forme di responsabilità, regolazione e nanotecnologie. Il Mulino, Bologna, pp 509549

13. Pellizzoni L (2005) Discutere l'incerto. In: Pellizzoni L (ed) La deliberazione pubblica. Meltemi, Roma, pp 91-114

14. van de Poel I (2009) The introduction of nanotechnology as a societal experiment. In: Arnaldi S, Lorenzet A, Russo F (eds) Managing the uncertainty of nanotechnology. Ios Press, Amsterdam, pp 129-142

15. Satterfield T, Conti J, Herr Harthorn B, Pidgeon N, Pitts A (2013) Understanding shifting perceptions of nanotechnologies and their implications for policy dialogues about emerging technologies. Science and Public Policy 40(2):247-260

16. von Schomberg R, Davies S (eds) (2010) Understanding public debate on nanotechnologies. Options for framing public policy. Publications Office of the European Union, Luxembourg 